\title{
Performance Evaluation for Global Virtual Teams (GVTs): Application of Data Envelopment Analysis (DEA)
}

\author{
M. Reza Hosseini ${ }^{1}$, Nicholas Chileshe ${ }^{1}$, Parviz Ghoddousi ${ }^{2}$, Gholam Reza Jahanshahloo ${ }^{2}$, Ali Katebi ${ }^{2} \&$ Mohsen \\ Saeedi $^{2}$ \\ ${ }^{1}$ University of South Australia, Australia \\ ${ }^{2}$ School of Civil Engineering, Iran University of Science \&Technology, Tehran, Iran
}

Correspondence: M. Reza Hosseini, University of South Australia, Australia. E-mail: mohammad.hosseini@unisa.edu.au

Received: July 1, 2013

doi:10.5539/ijbm.v8n19p122
Accepted: July 24, 2013

Online Published: September 18, 2013

URL: http://dx.doi.org/10.5539/ijbm.v8n19p122

\begin{abstract}
This paper builds all the discussions on an exhaustive literature review through critically investigating different aspects of managing GVTs concerning imposing control on virtual teams and measuring their performance. The foregoing features of managing GVTs have been regarded as problematic due to the idiosyncrasies of virtual team working. Besides, there are disagreementsin the literature regarding the necessity of implementing control and auditing for GVTs' context. To address the mentioned challenges, the crucial role of control and evaluating the performance of GVTs will be established based on the evidences from the litearture. Afterwards, the key requirements of performance evaluation for GVTs will be ascertained. Subsequently, the paper will briefly introduce Data Envelopment Analysis (DEA) as an available method for comparing and evaluating the performances of GVTs. The study will conclude by presenting guidelines to facilitate harnessing the abilities of DEA to measure the performance of GVTs and presenting directions for future studies in the area.
\end{abstract}

Keywords: global virtual teams, performance, control, management, DEA

\section{Introduction}

Many reports have advocated for the benefits of adopting GVTs. The great advantages envisaged for GVTs have been denoted by myriad of studies predicting an increasing trend for using GVTs in organisations in a wide range of industries (Duarte and Snyder, 2006, Hosseini and Chileshe, 2013a). Nevertheless, benefits of GVTs are achievable only by taking into account their unique idiosyncrasies and specific critical success factors (Camarinha-Matos and Afsarmanesh, 2003, Chang, 2011, Tong et al., 2013). In this context, many recent studies have enunciated that body of knowledge on GVTs is immature (Algesheimer et al., 2011, Schweitzer and Duxbury, 2010) and is not able to supply the field with adequate knowledge.

Hitherto, managerial issues have been identified as one of the main challenges of implementing GVTs in organisations. Specifically, the extant literature postulates that managers in charge of GVTs suffer from lack of methods and strategies for imposing control on their teams in which members are dispersed and mostly out of the reach by the manager of the team (Noori et al., 2009). Besides, GVT managers struggle to measure or evaluate the performance of members and the teams. In addition, many studies have underestimated the role of performance measurement by stressing the necessity of the empowerment of members in order to promote the self-controlling environment in GVTs. It seems the literature on GVTs has somehow shied away from presenting a workable solution to resolve the current situation and has literally overlooked the subject of control in GVTs.However, findings of the review of the literature showed that apart from primacy of empowerment, GVTs' managers do have to impose control on team members. Likewise, the performance control should be backed largely by means of deploying online devices and methods (Malhotra et al., 2007). On the other hand, performance of GVTs is affected by a wide range of factors from inside the team as well as from the surrounding environment. Hence, the managers are in need of methods possessing the ability to evaluate, measure, and compare the performance of entities under the effect of a wide range of variables and factors.

Many methods for measuring the performance of entities affected by many variables have been introduced including DEA as a robust tool for assessing the relative efficacy of Comparable Decision-Making Units (DMUs) (Ghoddousi et al., 2012). Authors are of the view that the forgoing method fits the requirements of measuring 
performance of GVTs as will be discussed in the following sections of this paper. The introduction of this method would be a rudimentary effort to bridge the gaps in the body of knowledge in terms of availability of practical methods for measuring the performnaces of virtual teams. Even more, the discussions presented within the study would settlethe disputesover the primacy of imposing control and performance measurement in GVTs. In addition, the study opens the door to lucrative grounds of research by making this proposition.

\section{Objectives of the Study}

Due to the disagrrements prevailing in the literature regarding the necessity of imposing control on GVTs and the lack of knowledge about practicable methods for measuring their performance, this paper attempts to provide answers for the below research questions as the focal point of the study:

1) Is it necessary to impose control and measure the performance of GVTs while many studies in the literature maintain that control and perforemnceaudits are not workable in GVTs?

2) If the answer to the above question is yes, what would be a practical method to fulfil the control requirements including evaluating the performace of GVTs?

\section{Research Methodology}

The paper takes advantage of the results of a broad literature review carried out on GVTs performance measurement along with tapping into the body of knowledge on DEA. Subsequently, the paper amalgamates and merges the information acquired, expresses the interpretations and eventually proposes the results as some guidelines for GVTs' managers. All the discussions and the conclusions of this research are built on analysing the extant literature. This seemed rationale in terms of robustness of the methodology as drawing upon the results of reviews of the literature as the sole method of studies has been widely experienced previously in some seminal inquiries about GVTs e.g. (Powell et al., 2004, Hertel et al., 2005).

In addition, literature on GVTs is not mature enough and is in need of creting knowledge to fill the existing gaps (Nordback and Sivunen, 2013, Caya et al., 2013). Likewise, lliterature review as a qualitative method is the first step of any research studywith the aim of extracting the available information from the existing body of knowledge. This phase has been titled as observation by Carlile and Christensen (2004) as the initial step towards theory building to create knowledge on a topic.

To assure the comprehensiveness of the literature considered, the review covered all the major databases such as Elsevier, Emerald, ISI web of science, Science-direct, Compendex, EBSCO, and ABI/INFORM. As well as the well-known databases, private bibliographic databases e.g. http://www.scoop.it/t/virtual-r-d-teamswere considered. Searching process were performed by using the keywords deployed in previous studies (Martins and Schilpzand, 2011, Hosseini and Chileshe, 2013a). Eventually, more than 350 publications relevant to the issue of GVTs were identified and reviewd.

\section{Global Virtual Teams (GVTs)}

\subsection{Concepts and Definitions}

The terminologies pertaining GVTs are still under evolution (Martins and Schilpzand, 2011). Hence, one widely agreed-upon definition for GVTs remains elusive(Chen and Messner, 2010, Martins and Schilpzand, 2011, Schweitzer and Duxbury, 2010, Mawanda, 2012, Wilson et al., 2013). Presenting in-length discussions on different approaches and the related definitions is beyond the scope of this paper. Therefore, we consider a recent definition of GVTs in this paper as:

"Groups of geographically, organisationally and/or time dispersed intelligent workers with different skills and in different positions of the hierarchy heavily relied on ICTS to accomplish tasks which for all are held accountable" (Hosseini \& Chileshe, 2013a, page 3).

Considering the foregoing definition, it is inferred that the nature of the relationships between the manager and the members in GVTs are far different from that of the conventional teams. It is because taking advantage of face-to-face meetings and negotiations (Hertel et al., 2005) and positive effects of non-job-related communications (Hofner Saphiere, 1996) are infeasible for GVTs. The unique attributes of GVTs such as the dispersions between the members and the managers dramatically affect their working environment and communications.

\subsection{Structure of GVTs}

Technical qualifications possessed by the team members are of high priority for GVTs' managers when it comes to selecting members. It is because one of the driving forces behind migrating to GVTs from the traditional 
system is to gain access to talented staff based on their technical competencies (Hosseini et al., 2013). In addition, managers face limitations in evaluating the socio-emotional attributes of members prior to inception of cooperation with them. As a result, GVTs' managers should select members solely on grounds of the technical skills prescribed by the objectives of the team (Harvey et al., 2004). The next step for managers would be dealing with the issues stemmed from challenges of having people from different cultures and with different working routines in one unit.

As stated, direct consequences of cultural diversity in GVTs are stemmed from the fact that team members come from very different backgrounds and with various experiences. Consequently, they bring with themselves different behavioural norms, organisational cultures, routines and assumptions about team working to GVTs (Kayworth and Leidner, 2002, Powell et al., 2004, Kozlowski and Ilgen, 2006). Some studies have asserted that cultural diversity in GVTs has dramatic effects on the performance of the team and gives rise to many serious issues in GVTs management (Hitson, 2008, Piccoli et al., 2004, Connaughton and Shuffler, 2007, Zimmermann, 2011). Major issues regarded as problematic due to the diversity dominant in GVTs include matters pertaining team cohesiveness (Martins and Schilpzand, 2011, Powell et al., 2004) and the identity of the team (O'Leary and Mortensen, 2011, Shapiro et al., 2002, Hertel et al., 2005). The mechanism of the influence of the virtuality of the team on the aforementioned variables and the concomitant impacts on GVTs' performance is still ambiguous within the literature.

Presumably, GVTs do not survive eliminating ICTs from the scene (Peters and Manz, 2007, Peansupap, 2012, LaLonde, 2011, Booth, 2011, Maynard and Gilson, 2013). The level of dependency of GVTs on ICTs has been suggested to act as one of the main attributes of GVTS and as the index of virtuality level for GVTs (Gibson and Gibbs, 2006). Some researchers have argued that ICTs interaction with GVTs is still a matter of controversy in academia (Curseu et al., 2008), since some scholars have contended that heavy reliance on ICTs is one of the concomitant outcomes of working in virtual environment for teams and could not be the cornerstone for theconcept of GVTs (Schweitzer and Duxbury, 2010). Nevertheless, the unprecedented advancements in ICTs have been the primary facilitator of the trend of utilising GVTs in organisations (Kirkman et al., 2004, Montoya-Weiss et al., 2001, Rezgui, 2001, Akhilesh et al., 2013).

Considering the idiosyncrasies and attributes of GVTs, it is inferred that managers of virtual teams confront unique challenges. These issues are mostly not of noticeable importance in traditional teams and presumably have not been addressedin the literature on conventional teams. The following sections expound on this matter.

\section{Challenges of Managing GVTs}

Studies have deployed different frameworks to investigate the issues of managing GVTs within the literature as in some studies authors have divided the lifecycle of a GVT into different phases. Many treatises have utilised the eminent method of categorising GVTs' lifecycle into teams inputs, outputs, and processes e.g.(Schiller and Mandviwalla, 2007). We considered the necessary tasks of managing a GVT to fall within three major consecutive phases. These phases include, Initiating, Executing/Performance managing/Team development, and Closing in accordance to the framework deployed in the paper by Hosseini and Chileshe (2013a).

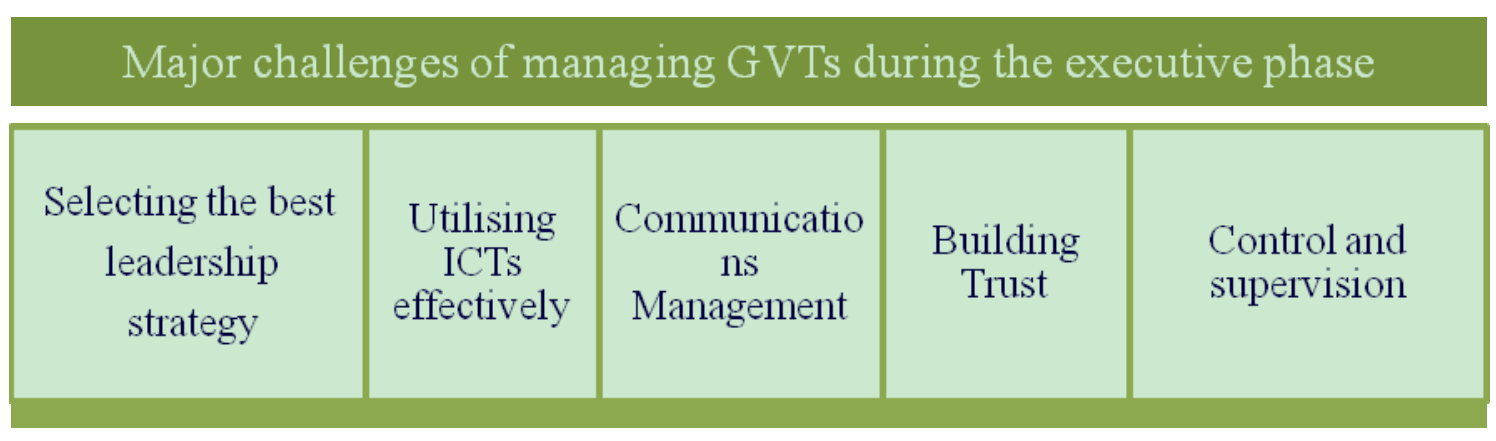

Figure 1. An abbreviated version of challenges of managing GVTs

As stated within the objectives of this paper, the focal points of the presented discussions concern the managerial aspects ofGVTs concerning control and performance audit of the team. Nevertheless, we should take 
into account the inherent interconnections and reciprocal effects between various features of managing GVTs throught the life cycle of the team. Hence, in order to clarify the corresponding issues, the following parts of the paper present a brief discussion on the main problematic aspects and challenges of managing GVTs. The items illustrated in figure 1 are the primary aspects of managing GVTs during the executive phase as will be expounded on in the following sections.

\subsection{Selecting the Best Leadership Strategy}

On the one hand, some studies have advocated for the viewpoint that selecting the appropriate leadership strategy would contribute enormously to the effectiveness of a GVT (Jarvenpaa and Tanriverdi, 2003, Kayworth and Leidner, 2002). Even more, some authors have claimed that the task of choosing the fitted leadership strategy could be the most challenging task for a manager in a GVT (Hertel et al., 2005, Bell and Kozlowski, 2002, Bal and Teo, 2001, Malhotra et al., 2007). On the other hand, the results of a broad research on this matter showed that the performance of a GVT is not affected directly by the nature of the relationships between the leader and the members (Goh, 2010). This perspectivequestions the theories supporting the crucial influence of leadership on the performance of GVTs.

Generally, it seems the autonomous task-oriented leadership styles which mostly should be implemented directly could not be effective in GVTs due to specific conditions dominant in their working environment (Hertel et al., 2005, Powell et al., 2004). Likewise, for managers of GVTs possessing specific leadership attributes seems a necessity (Bal and Teo, 2001). Nevertheless, identifying the effective leadership strategies fitting GVTs has been the objective of many studies (Malhotra et al., 2007, Van Pelt, 2010) whilst it is still a controversial matter in the related body of knowledge (Mukherjee et al., 2012, Mawanda, 2012). The salient samples of proposedleadership strategies for GVTs include the strategies drawing upon the approach of empowering personnel, and promoting self-managing policies (Hertel et al., 2005). We should acknowledge the achievements made by researchers in developing leadership frameworks even for specific contexts such as construction (Chinowsky et al., 2002, Chen and Messner, 2010), however the literature is not mature enough to clarify the ambiguities of selecting the appropriate leadership strategy for GVTs.

As a result, managers of GVTs are still deprived of an established agreed-upon leadership policy to be implemented in virtual team working environments. This is gaps of knowledge adversely affects the effectiveness of management practices in GVTs.

\subsection{Utilising ICTs Effectively}

Heavy reliance of GVTs on ICTs (Booth, 2011, Hosseini et al., 2012) increases their vulnerability to technological problems. In addition, the inferior quality of communications via ICTs in GVTs in comparison to conventional teams is another drawback of using ICTs as the main medium (Hertel et al., 2005). Therefore, GVTs' managers should be fully aware of the different patterns of information common in their teams, the nature and the type of the data necessary to be exchanged, and the best channels of communication based on the specific conditions of the team. On top of that, managers are confined by the abilities offered by ICTs in terms of controlling the performance of GVTs (Hosseini and Chileshe, 2013b) as will be discussed later in this paper.

\subsection{Communications Management}

Some studies have pointed out that GVTs personnel would experience large amounts of time loss on interpreting the communications and coordinating their activities due to the necessity of using ICTs as the central channel of communications (Maynard et al., 2012). Concisely, communications are problematic in GVTs as poor communications could be the source of many other problems encountered by managers and personnel of GVTs (Walvoord et al., 2008, Rosen et al., 2007, Lin et al., 2008, Duarte \& Snyder, 2006, Goodbody, 2005).

It is the well-known view within the literature indicating that every single project establishes its own communication patterns and takes advantage of specific communication tools. Besides, studies have asserted that modifying the patterns established previously might take great deal of effort and time. Therefore, setting effective rules of communication management at the initial stages of adopting a GVT is crucial for the managers (Martins and Schilpzand, 2011, Huysman et al., 2003).

\subsection{Building Trust}

The matters pertaning building trust in GVTs is one of the frequently mentioned aspects of managing GVTs in the extant literature. It is because developing trust between the members influencesthe performance of GVT's significantly (Henttonen \& Blomqvist, 2005, Malhotra et al., 2007, Khan, 2012). Moreover, the trend of trust development among members changes gradually and is largely determined by the stage of the lifecycle of the team (Kanawattanachai \& Yoo, 2002). Furthermore, trust development relies on the cultural backgrounds of the 
members as well (Yusof and Zakaria, 2012). However, the level of effect of trust on the GVT's performance varies based on the conditions of the team (Jarvenpaa et al., 2004). Nonetheless, some authors have expressed reservations about the strength of the correlationbetween developing trust among the members of GVTs and the outcomes of the team (Jarvenpaa et al., 2004). Thus, choosing effective measures for building trust among the members remains elusive for GVT's managers. Accordingly, the body of knowledge on trust development is still immature when it comes to GVTs as the managers face questions on how to implement effective managerial or leadership policies for promoting trust in GVTs (Crisp \& Jarvenpaa, 2013).

\subsection{Control and Supervision}

Managers in charge of GVTs lack an effective managerial tool namely the ability of exerting direct control and observational supervision (Hosseini \& Chileshe, 2013a, Rice et al., 2007), which could be one of the major challenges they face (Haywood, 1998, Piccoli et al., 2004, Bell \& Kozlowski, 2002). To resolve the mentioned issue, some published works have proposed supervision policies built on the idea of empowerment of team members in GVTs (Walvoord et al., 2008, Kirkman et al., 2004). Likewise, some studies have stated that GVTs with higher performance demonstrate the below attributes:

- Higher levels of dedication to teams' objectives;

- Team members act more cohesively;

- Members show balance between respect and harmony when it comes to dealing with the dissimilarities between members in the GVT (Ebrahim et al., 2009).

From another perspective, an important index for an acceptable level of performance in a GVTs could be the satisfaction of customers with the team (Kirkman et al., 2004). Extant literature suggests other performance metrics for GVTs including the quality of decisions made, quantity of ideas generated by the GVT, and how long it takes the team to make a decision as mentioned in some studies e.g. (Powell et al., 2004, Piccoli et al., 2004).

Generally, the issue of controlling the performance of GVTs is inseparable from the matters pertaining the leadership strategy, building trust, supervision policy and control methods. It seems that managers are in need of an integrated approach to address the challenges of performance measurement and control. In the envisaged integrated model, each construct is interrelated with others. As an example, selecting a specific leadership style affects the method for building trust and control policy. It seems promising but hitherto a validated integrated model is not available and all the foregoing issues are still controversial within the extant literature (Hertel et al., 2005). Taking into account the current situation, the next upcoming sections of the paper aim at expounding on the necessity of implementing control and performance measurement for GVTs based on the available knowledge and the variables that seem to be measurable in GVTs.

\section{GVTs Effectiveness/Performance}

The effectiveness of teams has become a major concern for organisations since at least two decades ago (Kozlowski \& Ilgen, 2006). Due to the crucial role of teams in organisations, researchers have put in a lot of effort to shed light on the mechanisms that teams draw upon to meet their defined objectives and the methods that make organisations capable of determining whether a team acts effectively or not (Bagozzi \& Dholakia, 2002, LePine et al., 2008). As a result, voluminous amount of relevant studies are available in the field, as a broad literature review from 2007 identified around 130 team performance models and frameworks (Salas et al., 2007). Nevertheless, the body of knowledge on the variables contributing to the performance of GVTs and the factors determining their effectiveness suffers from paucity of research (Algesheimer et al., 2011, Ebrahim et al., 2009). Researchers have acknowledged the great effects of variables related to social matters (Peters \& Karren, 2009, Lin et al., 2008), task-related variables (Lipnack and Stamps, 2000), and the quality of communications (Maznevski \& Chudoba, 2000, Ahn et al., 2005) on the effectiveness of GVTs. The comprehensive list of factors influencing the effectiveness of GVTs isnot available.Besides, using the currently identified variables in an integrated model to evaluate the level of the effectiveness of GVTs seems to be problematic as well. This is because the factors introduced in the literature are numerous whileseem to be incompatibleand highly diverse in nature. Moreover, collecting data from GVTs with dispersed members indistant locations is a demanding task (Lin et al., 2008).

It is noteworthy to mention that some studies e.g. (Algesheimer et al., 2011, Powell et al., 2004) did not clearly delineate the effectiveness and the performance in GVTs. Based on the previous applications for two terms in the relevant literature, we would contend that these words cannot be utilised interchangeably. Drawing upon the definitions presented by Piccoli et al. (2004), effectiveness could be defined as the quality and quantity of the 
outputs produced by the team along with the advantages team brings about for its members. Therefore, an effective GVT is the one with the capability of producing high quality outputs namely products or services. The effective GVT provides advantages for the team members by gratification and making them satisfied with their experience as well (Jarvenpaa \& Ives, 1994). Performance in turn could be defined as the level the products or services produced or provided by the GVT fulfils the requirements of the defined standards in terms of the quality along with the quantity and timeliness (Lurey \& Raisinghani, 2001, Martins \& Schilpzand, 2011). Therefore, in alignment with the model proposed by Lin et al. (2008) we assume that performance is the cornerstone of GVT's effectiveness and is correlated with the satisfaction level of the stakeholders, end-users and members of GVTs.

\subsection{Monitor/Control Performance in GVTs}

The below sections are the evidences from the literature establishing the necessity of implementing control and supervision on GVTs from different vantage points. The abbreviated version of the discussionsadvocating for the necessity of implementing performance control by managers of GVTs is illustrated in figure 2.

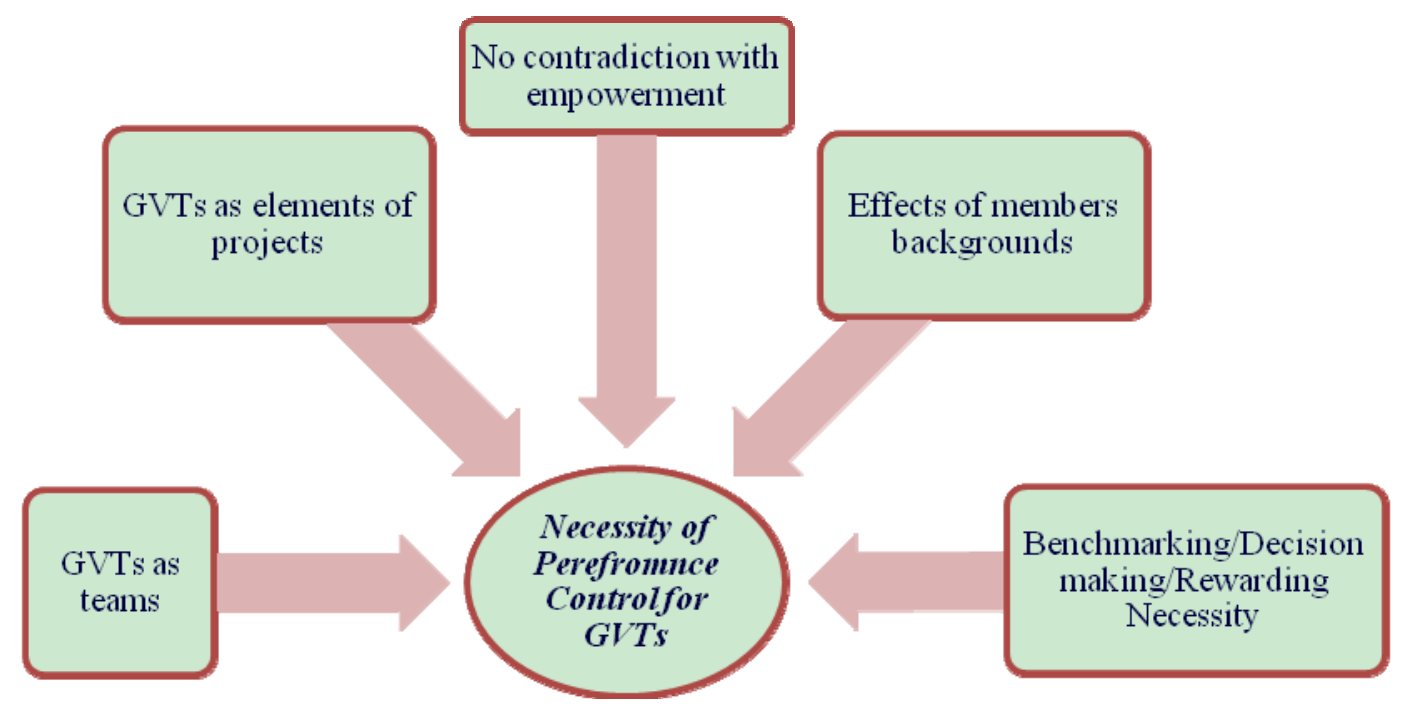

Figure 2. Justifications behind the necessity of implementing performance control for GVTs

\subsubsection{GVTs as Teams}

One of the main contributors to high levels of performance in teams is implementingeffective control policies (Hackman, 1990). The positive effects of control and performance evaluation have been endorsed by many studies. As an example, Paris et al. (2000, page 1055) in their broad review on team working stated, "without the measurement of team performance, one could not ascertain the success of any intervention to improve it". Building on the theories developed for conventional teams, the control mechanisms undertaken by managers of teams are the processes by which an organisation secures its movement through fulfilling the predefined objectives (Ouchi, 1979). The relevant tasks are literally among the essential managerial tasks and arecrucial for meeting the objectives of any organisation.

Apart from some unique idiosyncrasies, GVTs could be regarded as a team. Thus, the generic theories developed for teams in the literature seem to be applicable to GVTs (Piccoli et al., 2004), as many recent studies have considered GVTs solely as the novel structure of teams permeating organisations (Mukherjee et al., 2012, Wakefield et al., 2008). Considering GVTs as a team, the envisaged benefits of implementing control mechanism by the managers of GVTs applies to them based on the literature on team working. However, the aforementioned policies might bring about different levels of benefits and presumably must be adopted through other mechanisms in comparison to conventional teams.

\subsubsection{GVTs as Elements of Projects}

In many contexts, GVTs are serving the projects. Hence, according to one of the widely accepted guides of 
project management, meeting the requirements pertaining controlling, monitoring and auditing the performance of teams during the lifecycle of the project is central to the tasks supposed to be performed by any project manager (Project Management, 2008). We could consider a much more important role for monitoring and control in GVTs as virtual teams face greater project management challenges. Even one of the main critical success factors for GVTs has been identified as the ability of the project manager to set clear team goals and provide continuous performance feedback, which highlights the primacy of performance control in GVTs (Kayworth and Leidner, 2000). GVTs project management encompasses keeping the project on schedule and assuring that project goals remain unwavering (McDonough et al., 2001), reflecting the crucial role of performance control in GVTs.

\subsubsection{No Contradiction with Empowerment}

There are studies in GVTs' literature maintaining that optimal structural configuration for GVTs could be merely built on self-direction and empowerment of members. A salient example is the work by DeSanctis and Poole (1997) stating that teams migrating to work in a virtual environment require less formal procedures as the managerial control policies are not effectiveenough in GVTs. Literature on GVTs has traditionally advocated for the advantages of self-directing strategies (Jarvenpaa and Leidner, 1998, Jarvenpaa et al., 1998). Nevertheless, empirical studies have not approved the superiority of self-directed GVTs over the ones with managerial control systems. One is able to find studies advocating for the stromg correlation between empowerment of team members and effectiveness of the team (Kirkman et al., 2004), however the empowerment philosophy does not rule out the adoption of control and performance control through managerial control procedures. GVT members might retain little autonomy whilst members can still enjoy high levels of empowerment. Empowerment is dominant in a GVT as long as members share a collective feeling of potency, have acceptable levels of importance in their work, and are confident that the team's work brings about positive outcomes for its stakeholders (Spreitzer, 1995). On top of that, literature mostly deems empowerment to be a means of enhancing the motivation level of team members rather than a control policy. Hence, the rewarding system in place is also effective in terms of providing members with morale and motivation.

\subsubsection{Effects of Members' Backgrounds}

Due to the novelty of GVTs, most of the personnel working in GVTs come from traditional teams in which they had relied on supervision and a coordinator to tackle the challenges facing the team (Piccoli et al., 2004). In case of GVTs, the potential challenges facing the team are not trivial and include serious matters such as the problems stemmed from cultural diversity, communication poorness issues and the time taken to build trust among the members. The necessity of continuous control over GVTs working procedures seems central to the success of GVTs as reflected in the work by Pawar and Sharifi (1997) regarding sharing the experiences of a project adopting virtual teams. The authors stated that although every attempt was made to clarify and define the requirements and tasks precisely at the beginning of the project, yet frequently the tasks were not performed on schedule or the products did not meet the technical requirements.

\subsubsection{Bench Marking/Decision Making/Rewarding Necessity}

Apart from the direct managerial control issues, upper management levels of any organisation should be able to compare the performance of GVTs with other virtual teams. In some cases such as the preparation phases of the project, the managers in charge should have an accurate yardstick able to evaluate the rational of migrating to GVTs from conventional ones based on the degree of the effectiveness of the teams. Moreover, the questions regarding whether the performance of the team is getting worse or better during its lifecycle has not been addressed within the GVTs literature. The ability to measure the performance of the team is of vital importance from another point of view concerning the positive outcomes of rewarding systems on effectiveness of GVTs. It is because the establishment of a fair and appropriate rewarding system is one of the antecedents of virtual team working (Hertel et al., 2005, Bal and Teo, 2001). Studies pointed out that the performance of GVTs should be evaluated and rewarded as appropriate (Bal et al., 1999) as in the research conducted by Lurey and Raisinghani (2001) reward systems ranked as one of the essential supportive mechanisms for GVTs.

It seems supplying the managers with a performance measurement method acting as an accurate yardstckiscentral to the success of GVTs. As a result, from different vantage points GVTs are in need of managers able to undertake managerial control practices effectively. This fact has been echoed in some research studies within the literature on GVTs such as the works by Piccoli et al. (2004) and Piccoli and Ives (2000). However, identifying the effective methods to control and measure the performance of GVTs has been overlooked in the relevant literature as will be discussed in the below sections. 


\subsection{State of Research on Performance Control in GVTs}

Measuring the performance of a team takes having an instrument that is psychometrically rigorous while acting as an accurate yardstick for evaluating the performance of the team. Besides, the principles of the measurementmethod should be built on authentic theoretical principles (Baker and Salas, 1992). As stated before, performance is considered in the literature to be an element of team effectiveness (Mathieu et al., 2008). Thus, performance-measuring methods have roots in team effectiveness theories. The traditional approach to team effectiveness lends itself to deployment of the model advanced by McGrath (1964) as the input-process-output (IPO) framework. In IPO model, Inputsare related to antecedents and factors that enable and manipulate the interactions between team members. Examples could be characteristics essential for team members, variable of the team including the structure, organisational and working environment determinants. The collective effects of various antecedents will drive team processes. Processes play a vital role because they define how the team converts inputs into outputs. Outputs are the ultimate value-adding results gained out of team activities (Mathieu et al., 2000). Concisely, outputs of the team include two main elements namely the quality and quantity of the by-products of the team along with team members' satisfaction and job commitment (Mathieu et al., 2008). From this viewpoint, a major part of research studies on GVTs aim at identifying the factors associated with the inputs or processes of GVTs. Nevertheless, studies focusing on investigating the output aspects such as matters regarding outputcontrol and performance of the team are scarce in the extant literature.

We use the categorisation method introduced in the work ofSandberg and Alvesson (2011) for spotting the lack of research on GVTs performance in the existing literature. Table 1 illustrates a concise snapshot of the state of research on GVTs performance. It spots the gaps of knowledge based on three modes including application, neglect, and confusion. Confusion reflects the cases in which the knowledge is available in the literature whilst the views are contradictory, confusing, and competing. When we come across a case suffering from paucity of research or when the existing knowledge has overlooked the subject, we are dealing with the neglect mode that is the most common mode of gaps in research field. The gaps in the body of knowledge will be tilted as the neglect mode if the issue is still under investigation or sound empirical evidences to support the hypothesis are not available. When there is a need for extending, complementing, or altering the existing knowledge about a matter it falls within the application mode (Sandberg and Alvesson, 2011).

Table 1. Spotting the gaps of knowledge in research about GVTs performance

\begin{tabular}{|c|c|c|c|c|}
\hline \multirow{2}{*}{$\begin{array}{l}\text { Necessary } \\
\text { knowledge }\end{array}$} & \multirow{2}{*}{ State of knowledge in existing literature } & \multicolumn{3}{|c|}{ Gap-spotting in extant literature } \\
\hline & & Confusion & Neglect & Application \\
\hline Input & $\begin{array}{l}\text { Although there are some contradictions between the } \\
\text { researchers, the major enablers and antecedents of } \\
\text { effective GVTs are common in most of the available } \\
\text { studies. However, findings are mostly based on student } \\
\text { projects and are fragmented. Apparently, this category } \\
\text { is in need of extension and further research }\end{array}$ & & & $*$ \\
\hline Processes & $\begin{array}{l}\text { There are some available studies on how GVTs } \\
\text { develop during the lifecycle and the interactions } \\
\text { between members, leaders and managers. Yet, the area } \\
\text { is in need of further investigation. In this case there are } \\
\text { more competing viewpoints, thus this could be } \\
\text { regarded as the confusion mode }\end{array}$ & * & & \\
\hline $\begin{array}{l}\text { Output } \\
\text { (Performance) }\end{array}$ & $\begin{array}{l}\text { In alignment with the definition for neglecting mode as } \\
\text { no sound research study is available on the topic }\end{array}$ & & * & \\
\hline
\end{tabular}

The widest gap of knowledge is observedwhen it comes to output features of GVTs as evident in table 1 as will be dicussed in the following sections of the paper. 


\section{Discussions}

Drawing upon what reflected in table 1 and the discussions presented in previous sections, we arrive at the following conclusions:

(1) Vital importance of implementing managerial control and measuring the performance of teams is applicable to GVTs as there is no authentic evidence in favour of eliminating managerial control systems for GVTs. In contrast, we presented reasons to justify the necessity of exerting control over GVTs continuously (see figure 2).

(2) Output aspects of GVTsrequire conducting further research for ascertaining the affecting factors as well as providing the managers with appropriate methods to evaluate and measure the performance and satisfaction of members in GVTs.

(3) One of the neglected areas of research could be providing the field with a method enabling the managers to measure and evaluate the performance of GVTs based on the by-products of the team or according to the outputs produced by the team.

In response to the above statements, the authors are of the view that utilising Data Envelopment Analysis (DEA)might be the effective tool to resolve the highlighted issues. This is because, GVTs are frequently employed for projects with unique information requirements and their main tasks largely involve processing information such as calculations, designing or producing drawings. Therefore, DEA seems to be an effective tool for measuring the performance of GVTs. A concise description of the DEA method along with possible applications envisaged for measuring the performance of GVTs has been provided in the following section.

\subsection{Data Envelopment Analysis (DEA)}

It is Commonly admitted that, because of extra assumptions and prejudices in the growth of weights, the methods based on weighted average scores suffer from intrinsic weaknesses (El-Mashaleh et al., 2010). Nonetheless, DEA developed by Charnes, Cooper and Rhodes (1978) made an efficient frontier. The Decision Making Units (DMUs) which are perched on the frontier are regarded as efficient units because other units cannot create any more output by less or equal input. DEA draws upon linear programming to analyse the performance of units and allocates weights to the inputs and outputs. This method computes input and output weights of each DMU in order to maximise their performance. As another prominent trait of DEA, inputs and outputs should not be necessarily homogeneous (Charnes et al., 1978, Cooper et al., 2000). Hence, after the introduction of DEA, many studies in different fields have embarked on utilising DEA. We refer the interested readers to Cooper et al (2000) for more discussions on this topic. To evaluate the efficacy of issues such as power of countries, students' performance and leadership, only outputs can be used. In case of GVTs, a constant amount of input can be used for all the DMUs in the model (Liu et al., 2011, Ghoddousi et al., 2012).

\subsection{GVTs Performance Measurement Deploying DEA}

Aiming at evaluating the performance of GVTs deploying DEA, one should take into account the below items beforehand:

- What have been the driving forces for adopting GVTs in the first place?

- What do we expect from GVTs?

- What are the key performance indices of GVTs? (we should ascertain the KPIs for GVTs).

- What are the discrepancies between different GVTs?

- What are the factors outside the boundaries of the GVT affecting the success of the team?

After providing the answers for the aforementioned questions, designing the construct for evaluating the GVTs performancecould be initiatedentailing the below items:

(1) Identifying the key performance indices for GVTs.

(2) Defining the outputs and inputs of GVTs.

(3) Developing the proper layout for inputs and outputs based on the evaluation model objectives.

(4) Selecting the appropriate model for evaluating GVTs performance.

Preforming the above-mentioned stages effectively enables us to achieve the looked-for results out of evaluating GVTs performance. We should mention one caveat now concerning the fact that in this method, GVTs will be compared against each other. Weight of the indices for each team will be defined to show the highest performance. Hence, using more evaluation indices might culminate in having higher performance teams. This 
is the problem mostly encountered with basic DEA models, although novel models introduced recently have alleviated the related issues. Yet, it is preferable to deploy the minimum number of decision-making units, which is limited to 3 times of the sum of the output and input numbers of the system in question (Cooper, Seiford et al. 2000).

\section{Conclusions}

This study aimed at expounding on the issues of perfomnce management in GVTs by addressing the two primary challenges confronting managers of GVTs. Firstly, the findings showed that from any vantage point performance measurement in GVTs seems necessary and falls within the realm of crucial managerial tasks for GVTs' managers. Explicitly, the results established that promoting empowerment practices in GVTs seems vital however, measuring the performance of GVTs has no inconsistency with theories advocating for the essentiality of empowering staff in GVTs. This might be a mistake to regard empowerment as the substitude for the performance and control exertion in GVTs. Benefits of empowerment in GVTs does not rule out the primacy of performance measurement for virtual teams. Performance measurement is not only central to the increase of the effectiveness of GVTs, but also forms the building blocks of the process of benchmarking GVTs intra-organisationally as well as inter-organisationally. Even more, making any decision regarding migrating from traditional teams to GVTs takeshaving a deep appreciation of the performance of GVTs.

On the other hand, lack of knowledge on methods for measuring the performance of GVTs is obvious in the literature. It seems measuring the performance of GVTs grounded on the outputs of GVTs is literally neglected in the existing literature. As a rudimentary attempt to address the foregoing gap in the body of knowlegdethis studypoposes DEA as a workablemethod for measuring the performance of GVTs. Besides, some basic guidelines for deploying DEA as the performance measurement tool for GVTshave been provided. Nonetheless, the body of knowledge on GVTs is in need of knowledge creation on GVTs performance features prior to any attempt to use DEA. This fact is reflected in the future grounds for research on GVTs as the below items targeting the "what" aspects of the topic of interest:

- What are the main key performance indices (KPIs) for GVTs taking into account the driving forces behind migrating from traditional teams to GVTs and the primary objectives defined for GVTs in organisations?

- What might be the balance point between implementing control and supervision in GVTs and empowerment of members?

- What are the best tools to measure the performance of GVTs based on defined KPIs?

Next trend of research are those dealing with " why" questionsconcerning the necessity of clarifying:

- Why any selected method (e.g. DEA) could be the best solution to the problem of measuring performance in GVTs?

The above studies call for inquiries on GVTs in terms of supplying the research field with prerequisites for utilising DEA by trying to answer the "what" and "why" type questions. Another category of research studies should attempt to answer the "how" type questions by developing executive frameworks in order to facilitate using DEA as the potential tool for measuring the performance of GVTs. This category of studies should deal with questions such as the below:

- How can an organisation take the most out of deploying DEA as the tool for measuring the performance of GVTs?

We are of the view that directing future studies towards the abovementioned grounds would contribute to the body of knowledge on GVTs. The results of foregoing studies would promote implementing GVTs in organisations as the remedy to many challenges facing organisations in today's business environment.

In addition, deploying DEA as the method of performance measurement for GVTs might not be a straightforward solution for practitioners in the industry due to mathematical aspects of this method. Hence, it opens another door for future studies namely the necessity of using DEA as the basis for developing user-frinedlysoftwares and computer progremas that enable managers of GVTs of controlling the performnce of the team and individual team members based on the data received online.

Limitations of the study mostly concern the lack of empirical data to support the discussions and propositions of the study. Nevertheless, it provides future investigations with another fertile ground for inquiries to validate the discussions presented drawing upon empirical data form GVTs active in projects and organisations. Moreover, the perceptions of GVTs' managers regarding the feasibility of using methods such as DEA should be elicited from the orgnisations. Another limitation might be the problems with generalisation of the discussions for all the 
industries and all the cultures. Future researchers should consider substantiating the robustness of the discussions about the optimum point between exerting control and empowerment of members in different industries and withing different cultures.

\section{References}

Ahn, H. J., Lee, H. J., Cho, K., \& Park, S. J. (2005). Utilizing knowledge context in virtual collaborative work. Decision Support Systems, 39, 563-582. http://dx.doi.org/10.1016/j.dss.2004.03.005

Akhilesh, K. B., Sindhuja, C. V., \& Kahai, S. (2013). Extending Role of "I" Virtually-Identity Performance and Their Influence on Individual Behaviour and Team Performance in Globally Distributed Work Virtual Teams. In RAU, P. L. P. (Ed.), Cross-Cultural Design. Cultural Differences in Everyday Life. Springer Berlin Heidelberg.

Algesheimer, R., Dholakia, U. M., \& Gurău, C. (2011). Virtual team performance in a highly competitive environment. Group \& Organization Management, 36, 161-190. http://dx.doi.org/10.1177/1059601110391251

Bagozzi, R. P., \& Dholakia, U. M. (2002). Intentional social action in virtual communities. Journal of Interactive Marketing, 16, 2-21. http://dx.doi.org/10.1002/dir.10006

Baker, D. P., \& Salas, E. (1992). Principles for measuring teamwork skills. Human Factors: The Journal of the Human Factors and Ergonomics Society, 34, 469-475.

Bal, J., \& Teo, P. K. (2001). Implementing virtual teamworking: Part 2-a literature review. Logistics Information Management, 14, 208-222. http://dx.doi.org/10.1108/09576050110390248

Bal, J., Wilding, R., \& Gundry, J. (1999). Virtual teaming in the agile supply chain. International Journal of Logistics Management, 10, 71-82. http://dx.doi.org/10.1108/09574099910806003

Bell, B. S., \& Kozlowski, S. W. J. (2002). A typology of virtual teams. Group \& Organization Management, 27, 14-49. http://dx.doi.org/10.1177/1059601102027001003

Booth, B. (2011). Examining the Critical Factors of Success in Virtual Team Performance. Ph.D. 3442987, Northcentral University.

Camarinha-Matos, L. M., \& Afsarmanesh, H. (2003). Elements of a base VE infrastructure. Computers in Industry, 51, 139-163. http://dx.doi.org/10.1016/S0166-3615(03)00033-2

Carlile, P. R., \& Christensen, C. M. (2004). The cycles of theory building in management research.

Caya, O., Mortensen, M., \& Pinsonneault, A. (2013). Virtual Teams Demystified: An Integrative Framework for Understanding Virtual Teams. International Journal of e-Collaboration (IJeC), 9, 1-33. http://dx.doi.org/10.4018/jec.2013040101

Chang, C. M. (2011). New organizational designs for promoting creativity: A case study of virtual teams with anonymity and structured interactions. Journal of Engineering and Technology Management, 28, 268-282. http://dx.doi.org/10.1016/j.jengtecman.2011.06.004

Charnes, A., Cooper, W. W., \& Rhodes, E. (1978). Measuring the efficiency of decision making units. European Journal of Operational Research, 2, 429-444. http://dx.doi.org/10.1016/0377-2217(78)90138-8

Chen, C., \& Messner, J. I. (2010). A Recommended Practices System for a Global Virtual Engineering Team. Architectural Engineering and Design Management, 6, 207-221. http://dx.doi.org/10.3763/aedm.2010.0121

Chinowsky, P. S., Rojas, E., \& Team, U. O. T. (2002). Virtual teams: a guide to successful implementation. a report to Construction Industry Institute, the University of Texas at Austin. Construction Industry Institute.

Connaughton, S. L., \& Shuffler, M. (2007). Multinational and multicultural distributed teams. Small Group Research, 38, 387-412. http://dx.doi.org/10.1177/1046496407301970

Cooper, W. W., Seiford, L. M., \& Tone, K. (2000). Data envelopment analysis: a comprehensive text with models, applications, references, and DEA-Solver software. Kluwer Academic.

Crisp, C. B., \& Jarvenpaa, S. L. (2013). Swift Trust in Global Virtual Teams. Journal of Personnel Psychology, 12, 45-56. http://dx.doi.org/10.1027/1866-5888/a000075

Curseu, P. L., Schalk, R., \& Wessel, I. (2008). How do virtual teams process information? A literature review and implications for management. Journal of Managerial Psychology, 23, 628-652. 
http://dx.doi.org/10.1108/02683940810894729

Desanctis, G., \& Poole, M. S. (1997). Transitions in teamwork in new organizational forms. Advances in group Processes, 14, 157-176.

Duarte, D. L., \& Snyder, N. T. (2006). Mastering virtual teams: Strategies, tools, and techniques that succeed. Jossey-Bass Inc Pub.

Ebrahim, N. A., Ahmed, S., \& Taha, Z. (2009). Virtual Teams: A Literature Review. Australian Journal of Basic and Applied Sciences, 3, 2653-2669.

El-Mashaleh, M. S., Rababeh, S. M., \& Hyari, K. H. (2010). Utilizing data envelopment analysis to benchmark safety performance of construction contractors. International Journal of Project Management, 28, 61-67. http://dx.doi.org/10.1016/j.ijproman.2009.04.002

Ghoddousi, P., Jahanshahloo, G. R., Katebi, A., Saeedi, M., \& Honari, F. (2012). Identifying Comparative Leadership Styles Orientation in Power Plant Projects based on Data Envelopment Analysis (DEA). Archives Des Sciences, 56, 481-496.

Gibson, C. B., \& Gibbs, J. L. (2006). Unpacking the Concept of Virtuality: The Effects of Geographic Dispersion, Electronic Dependence, Dynamic Structure, and National Diversity on Team Innovation. Administrative Science Quarterly, 51, 451-495.

Goh, S. H. (2010). Leader-member relationships in virtual world teams. Ph.D. 3462304, The Florida State University.

Goodbody, J. (2005). Critical success factors for global virtual teams. Strategic Communication Management, 9 , $18-21$.

Hackman, J. R. (1990). Groups that work (and those that don't): creating conditions for effective teamwork. San Francisco, Jossey-Bass.

Harvey, M., Novicevic, M. M., \& Garrison, G. (2004). Challenges to staffing global virtual teams. Human Resource Management Review, 14, 275-294. http://dx.doi.org/10.1016/j.hrmr.2004.06.005

Haywood, M. (1998). Managing virtual teams: practical techniques for high-technology project managers. Boston: Artech House.

Henttonen, K., \& Blomqvist, K. (2005). Managing distance in a global virtual team: the evolution of trust through technology-mediated relational communication. Strategic Change, 14, 107-119. $\mathrm{http}: / / \mathrm{dx}$.doi.org/10.1002/jsc. 714

Hertel, G., Geister, S., \& Konradt, U. (2005). Managing virtual teams: A review of current empirical research. Human Resource Management Review, 15, 69-95. http://dx.doi.org/10.1016/j.hrmr.2005.01.002

Hitson, M. C. (2008). An analysis of leadership methodology and job satisfaction among virtual team members. D.M. 3324077, University of Phoenix.

Hofner Saphiere, D. M. (1996). Productive behaviors of global business teams. International Journal of Intercultural Relations, 20, 227-259. http://dx.doi.org/10.1002/jsc.714

Hosseini, M. R., \& Chileshe, N. (2013a). Global Virtual Engineering Teams (GVETs): A fertile ground for research in Australian construction projects context. International Journal of Project Management, http://dx.doi.org/10.1016/j.ijproman.2013.01.001

Hosseini, M. R., \& Chileshe, N. (2013b). Towards an Integrated Approach for Leading and Managing Transcultural Virtual Teams. In: CHRISTIANSEN, B., TURKINA, E. \& WILLIAMS, N. (eds.) Cultural and Technological Influences on Global Business. Hershey, Pennsylvania (USA): IGI Global. http://dx.doi.org/10.4014/978-1-4666-3966-9.ch012

Hosseini, M. R., Chileshe, N., Zuo, J., \& Baroudi, B. (2012). Approaches for implementing ICT technologies within construction industry. Australasian Journal of Construction Economics and Building, 1(2), 1-12.

Hosseini, M. R., Chileshe, N., Zuo, J., \& Baroudi, B. (2013). A Conceptual Framework for Member Selection in Global Virtual Teams (GVTs). In: SOLIMAN, K. S. \& YAACOB, M. R., eds. 20th IBIMA conference on Entrepreneurship Vision 2020: Innovation, Real Estate Investment, Development Sustainability, and Economic Growth 25-26 March 2013 Kuala Lumpur, Malaysia.

Huysman, M., Steinfield, C., Jang, C. Y., David, K., In't Veld, M. H., Poot, J., \& Mulder, I. (2003). Virtual teams and the appropriation of communication technology: Exploring the concept of media stickiness. Computer 
supported cooperative work (CSCW), 12, 411-436. http://dx.doi.org/10.1023/A:1026145017609

Jarvenpaa, S. L., \& Ives, B. (1994). The global network organization of the future: Information management opportunities and challenges. Journal of Management Information Systems, 25-57.

Jarvenpaa, S. L., Knoll, K., \& Leidner, D. E. (1998). Is anybody out there? Antecedents of trust in global virtual teams. Journal of Management Information Systems, 29-64.

Jarvenpaa, S. L., \& Leidner, D. E. (1998). Communication and trust in global virtual teams. Journal of Computer - Mediated Communication, 3.

Jarvenpaa, S. L., Shaw, T. R., \& Staples, D. S. (2004). Toward contextualized theories of trust: The role of trust in global virtual teams. Information systems research, 15, 250-267. http://dx.doi.org/10.1287/isre.1040.0028

Jarvenpaa, S. L., \& Tanriverdi, H. (2003). Leading virtual knowledge networks. Organizational Dynamics, 31, 403-412. http://dx.doi.org/10.1016/S0090-2616(02)00127-4

Kanawattanachai, P., \& Yoo, Y. (2002). Dynamic nature of trust in virtual teams. The Journal of Strategic Information Systems, 11, 187-213. http://dx.doi.org/10.1016/S0963-8687(02)00019-7

Kayworth, T., \& Leidner, D. (2000). The global virtual manager: a prescription for success. European Management Journal, 18, 183-194. http://dx.doi.org/10.1016/S0263-2373(99)00090-0

Kayworth, T. R., \& Leidner, D. E. (2002). Leadership effectiveness in global virtual teams. Journal of Management Information Systems, 18, 7-40. http://dx.doi.org/10.1504/IJNVO.2012.045210

Khan, M. S. (2012). Role of trust and relationships in geographically distributed teams: exploratory study on development sector. International Journal of Networking and Virtual Organisations, 10, 40-58.

Kirkman, B. L., Rosen, B., Tesluk, P. E., \& Gibson, C. B. (2004). The impact of team empowerment on virtual team performance: The moderating role of face-to-face interaction. The Academy of Management Journal, 175-192. http://dx.doi.org/10.2307/20159571

Kozlowski, S. W. J., \& Ilgen, D. R. (2006). Enhancing the effectiveness of work groups and teams. Psychological Science in the Public Interest, 7, 77-124.

Lalonde, K. (2011). Communication Among Virtual Teams. M.S. 1493595, The College of St. Scholastica.

Lepine, J. A., Piccolo, R. F., Jackson, C. L., Mathieu, J. E., \& Saul, J. R. (2008). A meta - analysis of teamwork processes: tests of a multidimensional model and relationships with team effectiveness criteria. Personnel Psychology, 61, 273 - 307. http://dx.doi.org/10.1111/j.1744-6570.2008.00114.x

Lin, C., Standing, C., \& Liu, Y. C. (2008). A model to develop effective virtual teams. Decision Support Systems, 45, 1031-1045. http://dx.doi.org/10.1016/j.dss.2008.04.002

Lipnack, J., \& Stamps, J. (2000). Virtual teams: People working across boundaries with technology.

Liu, W. B., Zhang, D. Q., Meng, W., Li, X. X., \& Xu, F. (2011). A study of DEA models without explicit inputs. Omega, 39, 472-480. http://dx.doi.org/10.1016/j.omega.2010.10.005

Lurey, J. S., \& Raisinghani, M. S. (2001). An empirical study of best practices in virtual teams. Information \& Management, 38, 523-544. http://dx.doi.org/10.1016/S0378-7206(01)00074-X

Malhotra, A., Majchrzak, A., \& Rosen, B. (2007). Leading virtual teams. The Academy of Management Perspectives Archive, 21, 60-69. http://dx.doi.org/10.5465/AMP.2007.24286164

Martins, L. L. \& Schilpzand, M. C. (2011). Global Virtual Teams: Key Developments, Research Gaps, and Future Directions. Research in Personnel and Human Resources Management, 30. http://dx.doi.org/10.1108/S0742-7301(2011)0000030003

Mathieu, J., Maynard, M. T., Rapp, T., \& Gilson, L. (2008). Team effectiveness 1997-2007: A review of recent advancements and a glimpse into the future. Journal of Management, 34, 410-476. http://dx.doi.org/10.1177/0149206308316061

Mathieu, J. E., Heffner, T. S., Goodwin, G. F., Salas, E., \& Cannon-Bowers, J. A. (2000). The influence of shared mental models on team process and performance. Journal of Applied Psychology, 85, 273. http://dx.doi.org/10.1037/0021-9010.85.2.273

Mawanda, H. J. (2012). Beyond technology, an analysis of the perceived impact of transformational leadership and contingent rewards as extrinsic motivation on virtual team member satisfaction and leadership 
effectiveness: A quantitative study. Ph.D. 3503075, Capella University.

Maynard, M. T., \& Gilson, L. L. (2013). The Role of Shared Mental Model Development in Understanding Virtual Team Effectiveness. Group \& Organization Management. http://dx.doi.org/10.1177/1059601113475361

Maynard, M. T., Mathieu, J. E., Rapp, T. L., \& Gilson, L. L. (2012). Something(s) old and something(s) new: Modeling drivers of global virtual team effectiveness. Journal of Organizational Behavior, 33, 342-365. http://dx.doi.org/10.1002/job.1772

Maznevski, M. L., \& Chudoba, K. M. (2000). Bridging space over time: Global virtual team dynamics and effectiveness. Organization science, 473-492. http://dx.doi.org/10.1287/orsc.11.5.473.15200

Mcgrath, J. E. (1964). Social psychology: a brief introduction. New York: Holt, Rinehart \& Winston, Holt, Rinehart and Winston.

Montoya-Weiss, M. M., Massey, A. P., \& Song, M. (2001). Getting it together: Temporal coordination and conflict management in global virtual teams. Academy of Management Journal, 1251-1262. http://dx.doi.org/10.2307/3069399

Mukherjee, D., Lahiri, S., \& Billing, T. K. (2012). Leading virtual teams: How do social, cognitive, and behavioral capabilities matter? Management Decision, 50, 6-6. http://dx.doi.org/10.1108/00251741211203560

Noori, S., Hosseini, S. H., \& Bakhsha, A. (2009). Human performance factors in the evaluation of virtual organizations. International Journal of Business and Management, 4, 41.

Nordback, E., \& Sivunen, A. (2013). Leadership Behaviors in Virtual Team Meetings Taking Place in a 3D Virtual World. System Sciences (HICSS), 2013 46th Hawaii International Conference on, 7-10 Jan. 2013 2013. 863-872. http://dx.doi.org/10.1109/HICSS.2013.380

O'leary, M., \& Mortensen, M. (2011). Go (con) figure: Subgroups, imbalance, and isolates in geographically dispersed teams.

Ouchi, W. G. (1979). A conceptual framework for the design of organizational control mechanisms. Management Science, 25, 833-848. http://dx.doi.org/10.1287/mnsc.25.9.833

Paris, C. R., Salas, E., \& Cannon-Bowers, J. A. (2000). Teamwork in multi-person systems: a review and analysis. Ergonomics, 43, 1052-1075. http://dx.doi.org/10.1080/00140130050084879

Pawar, K. S., \& Sharifi, S. (1997). Physical or virtual team collocation: Does it matter? International Journal of Production Economics, 52, 283-290. http://dx.doi.org/10.1016/S0925-5273(97)89241-9

Peansupap, V. (2012). An exploratory approach to the diffusion of ICT in a project environment.

Peters, L., \& Karren, R. J. (2009). An examination of the roles of trust and functional diversity on virtual team performance ratings. Group \& Organization Management, 34, 479-504. http://dx.doi.org/10.1177/1059601107312170

Peters, L. M., \& Manz, C. C. (2007). Identifying antecedents of virtual team collaboration. Team Performance Management, 13, 117-129. http://dx.doi.org/10.1108/13527590710759865

Piccoli, G., \& Ives, B. (2000). Virtual teams: managerial behavior control's impact on team effectiveness. Proceedings of the twenty first international conference on Information systems, 2000. Association for Information Systems, 575-580.

Piccoli, G., Powell, A., \& Ives, B. (2004). Virtual teams: team control structure, work processes, and team $\begin{array}{llllll}\text { effectiveness. Information Technology } \& \quad \text { People, } & 17, & \text { 359-379. }\end{array}$ http://dx.doi.org/10.1108/09593840410570258

Powell, A., Piccoli, G., \& Ives, B. (2004). Virtual Teams: A Review of Current Literature and Directions for Future Research1. Database for Advances in Information Systems, 35, 6-36. http://dx.doi.org/10.1145/968464.968467

Project Management, I. (2008). A guide to the project management body of knowledge (PMBOK® Guide), Newtown Square, Pa, Project Management Institute, Inc.

Rezgui, Y. (2001). Review of information and the state of the art of knowledge management practices in the construction industry. The Knowledge Engineering Review, 16, 241-254. http://dx.doi.org/10.1017/S026988890100008X 
Rice, D. J., Davidson, B. D., Dannenhoffer, J. F., \& Gay, G. K. (2007). Improving the effectiveness of virtual teams by adapting team processes. Computer Supported Cooperative Work (CSCW), 16, 567-594. http://dx.doi.org/10.1007/s10606-007-9070-3

Rosen, B., Furst, S., \& Blackburn, R. (2007). Overcoming Barriers to Knowledge Sharing in Virtual Teams. Organizational Dynamics, 36, 259-273. http://dx.doi.org/10.1016/j.orgdyn.2007.04.007

Salas, E., Stagl, K. C., Burke, C. S., \& Goodwin, G. F. (2007). Fostering team effectiveness in organizations: Toward an integrative theoretical framework. Nebraska Symposium on Motivation, 2007. 185.

Sandberg, J., \& Alvesson, M. (2011). Ways of constructing research questions: gap-spotting or problematization? Organization, 18, 23-44. http://dx.doi.org/10.1177/1350508410372151

Schiller, S. Z., \& Mandviwalla, M. (2007). Virtual Team Research. Small Group Research, 38, 12-59. http://dx.doi.org/10.1177/1046496406297035

Schweitzer, L., \& Duxbury, L. (2010). Conceptualizing and measuring the virtuality of teams. Information Systems Journal, 20, 267-295. http://dx.doi.org/10.1111/j.1365-2575.2009.00326.x

Shapiro, D. L., Furst, S. A., Spreitzer, G. M., \& Von Glinow, M. A. (2002). Transnational teams in the electronic age: are team identity and high performance at risk? Journal of Organizational Behavior, 23, 455-467. http://dx.doi.org/10.1002/job.149

Spreitzer, G. M. (1995). Psychological, Empowerment In The Workplace: Dimensions, Measurement And Validation. Academy of Management Journal, 38, 1442-1465. http://dx.doi.org/10.2307/256865

Tong, Y., Yang, X., \& Teo, H. H. (2013). Spontaneous virtual teams: Improving organizational performance through information and communication technology. Business Horizons, 56, 361-375. http://dx.doi.org/10.1016/j.bushor.2013.01.003

Van Pelt, S. (2010). The complexities of leading virtual teams: A phenomenological study. University Of Phoenix.

Wakefield, R. L., Leidner, D. E., \& Garrison, G. (2008). Research Note-A Model of Conflict, Leadership, and Performance in Virtual Teams. Information Systems Research, 19, 434-455. http://dx.doi.org/10.1287/isre.1070.0149

Walvoord, A. A. G., Redden, E. R., Elliott, L. R., \& Coovert, M. D. (2008). Empowering followers in virtual teams: Guiding principles from theory and practice. Computers in Human Behavior, 24, 1884-1906. http://dx.doi.org/10.1016/j.chb.2008.02.006

Wilson, J., Crisp, C. B., \& Mortensen, M. (2013). Extending Construal-Level Theory to Distributed Groups: Understanding the Effects of Virtuality. Organization Science, 24, 629-644. http://dx.doi.org/10.1287/orsc.1120.0750

Yusof, S. A. M., \& Zakaria, N. (2012). Exploring the State of Discipline on the Formation of Swift Trust within Global Virtual Teams. 2012. IEEE, 475-482.

Zimmermann, A. (2011). Interpersonal relationships in transnational, virtual teams: Towards a configurational perspective. International Journal of Management Reviews, 13, 59-78. http://dx.doi.org/10.1111/j.1468-2370.2010.00284.x

\section{Copyrights}

Copyright for this article is retained by the author(s), with first publication rights granted to the journal.

This is an open-access article distributed under the terms and conditions of the Creative Commons Attribution license (http://creativecommons.org/licenses/by/3.0/). 